\title{
Construction of Teaching Simulation Platform in College English Curriculum System
}

\author{
Ke QIN \\ Guizhou University of Finance and Economics; Guiyang, Guizhou, China. 550025 \\ KeQIN109@yeah.net
}

Keywords: college English; teaching; simulation platform; prospects

\begin{abstract}
With the deepening and development of globalization, as the international language, English has become one of the compulsory language courses in Chinese schools. In order to improve the quality of English teaching and improve students' English level, major colleges and universities are carrying out research work in English language teaching curriculum system, from which the construction of English teaching simulation platform has been widespread concerned by teachers and students. This paper introduces the concept of college English curriculum system teaching simulation platform, analyzes the characteristics and development prospects and proposes a series of related reasonable proposals.
\end{abstract}

\section{Introduction}

The ultimate goal of learning all knowledge is for practical application, however, due to the current situation of China's education more favor exam-oriented education, which makes English teaching old-fashioned, stiff and severely reduce students' interest and contrary to the original intention of English teaching. Therefore, the English practice must be made as the main task of English teaching. teaching the use of simulation for students to learn in a simulation environment to improve students' language proficiency. Note that the construction of teaching simulation platform must do systematic curriculum design, interactive system design, and strengthen the construction of teachers to improve the application ability of teachers to the platform.

\section{Analysis on college English curriculum system simulation teaching}

\section{Concepts of teaching simulation and simulation platform}

Simulation teaching is a teaching method emerging in recent years with the development of computer network technology, which has been widely used. Simulation teaching is also known as analog pedagogy, which is a teaching style that simulates a real learning environment for students through computer software to learn through network in the simulation environment. In the process of simulation learning, the combination of computer software and online networks provide students with a realistic scenario, for example, students can dialogue with characters in the virtual environment by English on the network and help students apply the knowledge learned to the actual dialogue to consolidate the theoretical foundation and improve oral proficiency. The applied network technology and computer software in the simulation teaching constitutes the simulation teaching platform. 


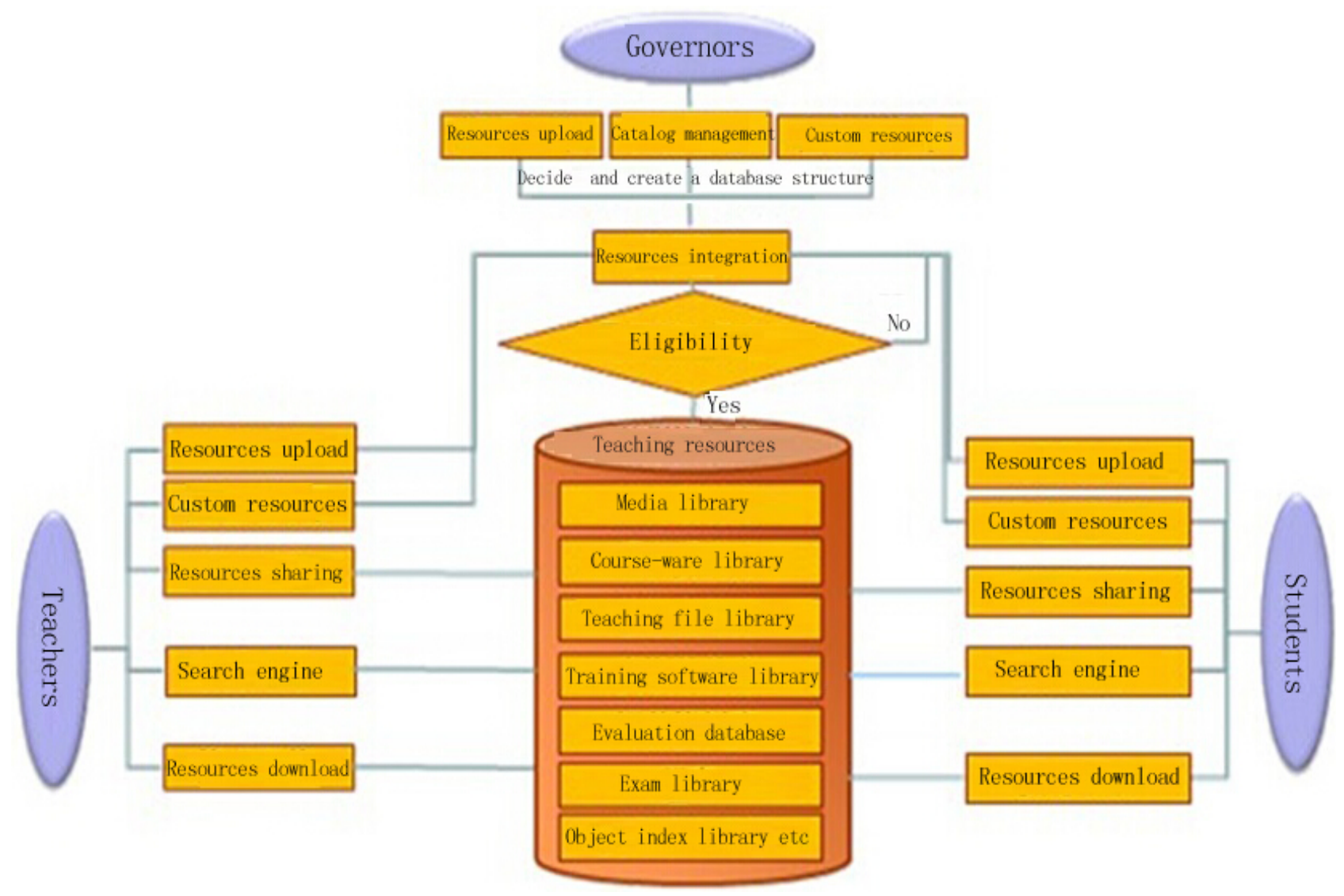

Figure 1 Teaching Stimulation Platform

\section{Analysis on features of simulation platform}

1) Initiative. Simulation platform software can operate independently. The students can arrange and autonomous choose learning time and learning content according to their own schedule, which effectively get rid of students must be on time in the traditional classroom teaching and passively accepting of the limits of knowledge.

2) Pertinence. The traditional teaching method is one to more, in which it is hard for one teacher to take care of every student's shortage and can not repeatedly explain every part of the knowledge to care for the majority of students. Students learn independently through simulation platform and directly understand their own existence inadequacies through feedback function of software and then repeatedly learning and training.

3) Practicality. It breaks original teaching mode which conducts firstly theory learning and then practice. In traditional teaching, long time theory accumulation the first and then uniform organizational practice. While the construction of simulation platform can make students practice at the time of theory learning, which can deepen their understanding of the theory, thus it can be said that the simulation platform is a practicality teaching.

4) Resource sharing and interactivity. Simulation teaching platform is established relying on a network, so it can realize information sharing and exchange between different computers and provide students with a rich learning resources to meet the needs of every student to be used to focus on teaching and improve teaching efficiency.

\section{How to build a teaching simulation platform for college English curriculum system}

\section{Systematic courses designation}

First, you must ensure to the selected courses suitable for network simulation platform. we should know that in college English curriculum system, the spoken English is most suitable for simulation platform, while writing is not very suitable. The use of simulation systems to avoid weaknesses, we should focus on the use of simulation platform to strengthen spoken exercises and 
naturally other series English proficiency will be strengthened. Also, the selection of course should be comprehensive, systematic and can comprehensively improve students' comprehensive ability. College English courses can be divided into the following series, language-based series, language application series, cultural knowledge series. The series can be divided into blocks to respectively simulate and then integrated learn each series and mutual promote to comprehensively improve the English level.

\section{An interactive system design}

College English curriculum system teaching simulation platform is mainly based on computer software and re-emerged a simulated and real learning environment. So in computer software design, pay attention to the development of interactive sessions and sub-module for teaching activities to make students and computer systems as well as students and teachers timely interact with each other and can design independent learning modules, and student self-detection module, the teacher online Q \& A module, the team simulated situations online dialogue module and so on, and timely feedback to students performance and affirm or give suggestions.

\section{Strengthen the construction of teachers}

The use of college English curriculum system teaching simulation platform needs a number of professional quality teachers, who have to be trained to master the use of simulation system and know about frequent appearing software problems to improve problem-solving skills and are used to complete daily teaching by simulation platform. To focus on the training of teachers, in the initial introduction of simulation platform, hold training sessions and a series of lectures, organize teachers to observe outstanding teaching to make teachers learn how to use the software first, and then regularly convene exchanging meetings to gradually summary experiences and improve the practice level of teachers.

\section{Construction of multi-oriented simulation platform}

Currently, the simulation platform construction of college English teaching curriculum system can be roughly divided into four dominant types: government-oriented, corporate-oriented, school-oriented, individual-oriented. First, the government-oriented type means that the government funds to construct simulation platform and to develop software, playing the policy role of government for resources sharing across regions. Therefore, in the future development, the construction of simulation platform needs to rely on the financial support of the education sector to provide funding and policy. Second, the corporate-oriented type means school-enterprise cooperation, large enterprises provide internship opportunities for schools so as to provide a platform for students to transform theory into practice, making teaching achievement play its role. Third, we must rely on a leading role of school and encourage students to join in the application of the simulation platform so as to allow students to contact foreign language closely, using English and experiencing English knowledge in a highly realistic environment in order to achieve the fundamental purpose of English teaching.

\section{Development prospects of simulation platform}

Construction of college English teaching simulation platform needs the support of a lot of money and resources and it is difficult to get into better development solely relying on the school. In the future construction process of simulation platform of college English system, the construction model of corporate-oriented corporate-school combination needs to adhere to the professional construction mode featuring professional knowledge, school simulation and corporate practice. First, optimize the course content design of simulation platform, curriculum content needs to constantly adapt to new skills and new requirements, and to be student-centered and ability-oriented. Integrate teaching content orienting corporate-school combination, teaching and training content adjusts and updates timely in accordance with modern enterprise requirements for business personnel, school training base should be designed as simulation training center in accordance with the actual business environment, and should update and upgrade with the changes of business requirements, skills, equipment and specification, strengthen the practice operating capability of English majors in accordance with modern enterprise management methods for business English talent, so that 
students can meet the professional ethics and quality of enterprise, "adapt to the real work environment and qualify various vocational skills of the English application talents”.

\section{Conclusion}

In summary, the construction of college English curriculum system simulation platform can not only save a lot of manpower, space resources and also effectively enhance students' English proficiency. Therefore, the colleges must pay attention to the construction of simulation platform of English teaching and provide students with a better way to learn. I believe that with the development of computer network technology, the results of simulation platform will be better and its usefulness will be further improved.

\section{References}

[1] Li Can. Study on Simulation Training of Spoken English in College English Teaching [J]. Value Engineering, 2014,17: 249-250.

[2] Cao Yang, Zhang Yu. English Teaching in Simulation Environment [J] Technology Horizon, 2014,11

[3] Liu Guang. Exploration on the Applications of Network Simulation Tool in University Network Computer Teaching [J] Modern Educational Technology, 2009,10: 111-113 + 106.

[4] Zeng Xiaoshan. Study on Teachers Hidden Curriculum in University English Curriculum Implementation [D]. Shanghai Foreign Language University, 2013.

[5] Sui Xiaobing. Study on university English class teaching optimization in the network environment [D] . Shanghai Foreign Language University, 2013. 